\title{
Surgical decontamination in ferrous sulfate intoxication
}

\author{
Jung-In Ko ${ }^{1}$, Kyung Su Kim², Gil Joon Suh ${ }^{2,3}$, Seong-Ho Kong ${ }^{4}$, Yoon Sun Jung ${ }^{2}$
}

${ }^{1}$ Department of Emergency Medicine, National Medical Center, Seoul; ${ }^{2}$ Department of Emergency Medicine, Seoul National University Hospital, Seoul; ${ }^{3}$ Department of Emergency Medicine, Seoul National University College of Medicine, Seoul; ${ }^{4}$ Department of Surgery, Seoul National University Hospital, Seoul, Korea

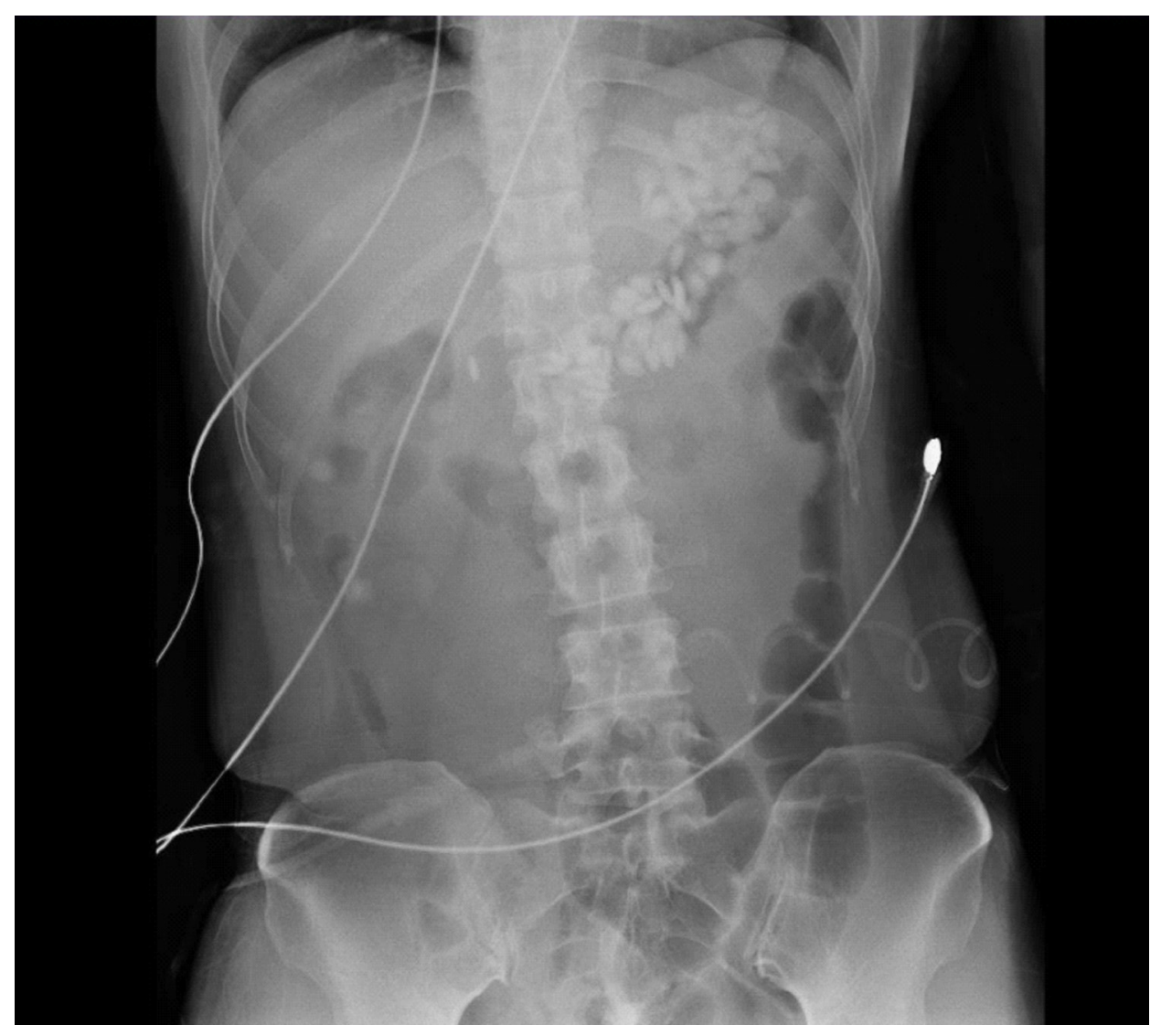

Figure 1. Abdominal plain radiograph. Most tablets remained inside the stomach.

A 32-year-old woman was transferred to the emergency room after ingestion of 200 tablets of $80 \mathrm{mg}$ ferrous sulfate for suicide. She received gastric lavage 30 minutes after ingestion and activated charcoal before transfer. Most tablets remained inside the stomach on abdominal plain radiography (Figure 1). The initial serum iron level was $326 \mu \mathrm{g} / \mathrm{dl}$ (normal range, 50 to $130 \mu \mathrm{g} / \mathrm{dl}$ ), and deferoxamine therapy was started with $15 \mathrm{mg} / \mathrm{kg} / \mathrm{hr}$ for 24 hours. Emergency

\section{Image in Critical Care}

Received: December 24, 2018

Revised: April 12, 2019

Accepted: April 12, 2019

\section{Corresponding author} Kyung Su Kim

Division of Critical Care, Department of Emergency Medicine, Seoul National University Hospital, 101 Daehak-ro, Jongno-gu, Seoul 03080, Korea

Tel: +82-2-2072-4751

Fax: +82-2-741-7855

E-mail: kanesu@gmail.com

Copyright () 2019 The Korean Society of Critical Care Medicine

This is an Open Access article distributed under the terms of Creative Attributions Non-Commercial License (http://

creativecommons.org/li-censes/by-nc/4.0/) which permits unrestricted noncommercial use, distribution, and reproduction in any medium, provided the original work is properly cited. 
endoscopy was performed 15 hours after ingestion. Not all tablets could be removed because of increased bleeding tendency due to black granules covering the gastric mucosa and numerous tangled tablets (Figure 2). At 23 hours after ingestion, she underwent emergency laparotomy, and a total of 114 tablets was removed (Figures 3 and 4). Serum iron level was normalized at the day after surgery.
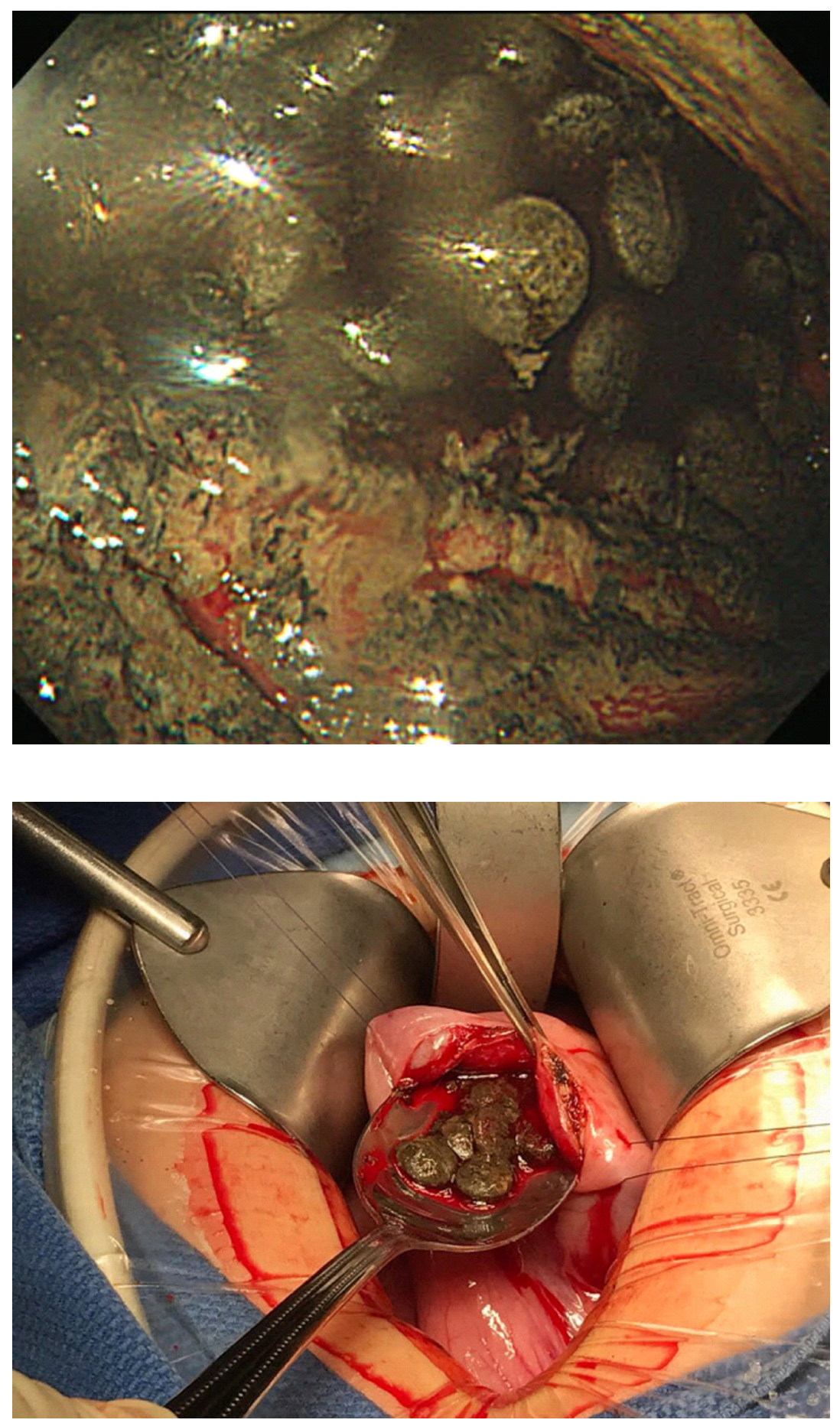

In this case, without mechanical removal, the ingested tablets would have remained in the stomach for a long time. Instead, the patient recovered after emergency laparotomy. In conclusion, surgical removal may be an option if endoscopic decontamination is impossible for early decontamination in acute iron intoxication.
Figure 2. Emergency endoscopic findings. The stomach mucosa was covered with black granules, and many tablets were tangled and stuck to the stomach wall.
Figure 3. Emergency laparotomy and tablet removal. 


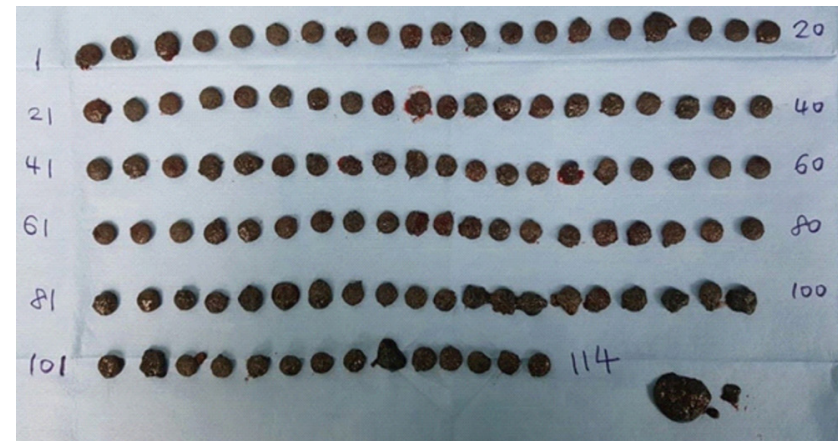

Figure 4. The surgically removed tablets.

\section{CONFLICT OF INTEREST}

No potential conflict of interest relevant to this article was reported.

\section{ACKNOWLEDGMENTS}

This case report was approved by the Institutional Review Board of study hospital (IRB No. 1712-162-913) and written informed consent was waived.

\section{ORCID}

Jung-In Ko https://orcid.org/0000-0001-5211-6484 Kyung Su Kim https://orcid.org/0000-0002-3897-0278

Gil Joon Suh https://orcid.org/0000-0001-5163-2217

Seong-Ho Kong https://orcid.org/0000-0002-3929-796X

Yoon Sun Jung https://orcid.org/0000-0001-7408-4436

\section{AUTHOR CONTRIBUTIONS}

Conceptualization: KSK, GJS. Data curation: JIK, SHK. Writing - original draft: JIK, KSK. Writing - review \& editing: GJS, SHK, YSJ. 